\title{
Damage Analysis and Evaluation of High Strength Concrete Frame Based on Deformation-Energy Damage Model
}

\author{
Huang-bin Lin, ${ }^{1}$ Shou-gao Tang, ${ }^{1}$ and Cheng Lan ${ }^{2}$ \\ ${ }^{1}$ School of Aerospace Engineering and Applied Mechanics, Tongji University, Shanghai 200092, China \\ ${ }^{2}$ Bolina Ingegneria S.R.L., Mestre, 30173 Venice, Italy \\ Correspondence should be addressed to Huang-bin Lin; 1110448@tongji.edu.cn
}

Received 18 August 2014; Accepted 24 November 2014

Academic Editor: Yuri Petryna

Copyright (c) 2015 Huang-bin Lin et al. This is an open access article distributed under the Creative Commons Attribution License, which permits unrestricted use, distribution, and reproduction in any medium, provided the original work is properly cited.

\begin{abstract}
A new method of characterizing the damage of high strength concrete structures is presented, which is based on the deformation energy double parameters damage model and incorporates both of the main forms of damage by earthquakes: first time damage beyond destruction and energy consumption. Firstly, test data of high strength reinforced concrete (RC) columns were evaluated. Then, the relationship between stiffness degradation, strength degradation, and ductility performance was obtained. And an expression for damage in terms of model parameters was determined, as well as the critical input data for the restoring force model to be used in analytical damage evaluation. Experimentally, the unloading stiffness was found to be related to the cycle number. Then, a correction for this changing was applied to better describe the unloading phenomenon and compensate for the shortcomings of structure elastic-plastic time history analysis. The above algorithm was embedded into an IDARC program. Finally, a case study of high strength RC multistory frames was presented. Under various seismic wave inputs, the structural damages were predicted. The damage model and correction algorithm of stiffness unloading were proved to be suitable and applicable in engineering design and damage evaluation of a high strength concrete structure.
\end{abstract}

\section{Introduction}

Structural concrete is a material with quite outstanding cumulative damage characteristics; however, damage development and damage accumulation under different conditions are fundamental for understanding structural failure. Seismic damage greatly influences the bearing capacity of a building or structure during the follow-up service period and remaining life. Structural damage and its accumulation occur under dynamic loading, and a reasonable damage model must be constructed so that the damage can be described.

The structure damage caused by earthquakes is closely related to the maximum structural deformation and the low cycle fatigue effect caused by the accumulation of damage. In this paper, we have adopted a model based on two major forms of seismic damage [1]: (1) damage which occurs the first time the structure is taken beyond initial cracking and (2) damage due to subsequent energy dissipation. These forms of damage are incorporated into a double parameter damage model based on deformation and energy dissipation.

In this paper, we use the stiffness degradation trilinear model (DT3 model, Figure 1). The DT3 model uses three lines to describe the loading and restoring force skeleton curve and considers the stiffness degradation properties of the reinforced concrete structure or structural component. The model can describe in more detail the real restoring force curve of a reinforced concrete structure. Depending on whether a particular structure or structural member is expected to harden after yielding, the curve is divided into two parts-one part using the maximum top hardening degradation from the trilinear model, while the other part without this consideration. The degradation trilinear model, as used in this paper, is widely applied in engineering projects.

For these structures, the elastic-plastic time history analyses of the structure are carried out in order to determine the effect of accumulated damage on performance. Since 


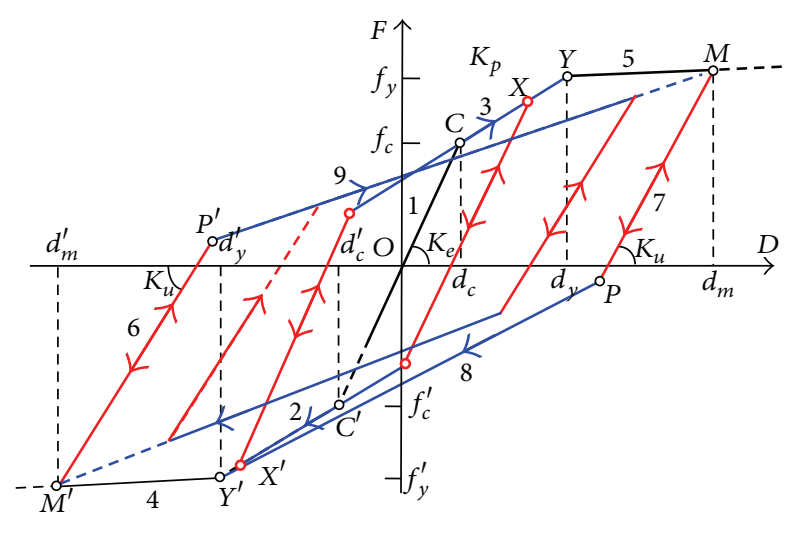

FIGURE 1: Degrading trilinear model (DT3).

the relationship between the unloading stiffness and ductility coefficient is also unknown, IDARC [2] analysis is introduced in this paper (Scheme 1).

\section{Parameter Determination for Deformation- Energy Damage Model of High Strength Concrete}

2.1. Model for Deformation-Energy Consumption Damage. We chose the Park and Ang's double parameters damage model for this paper [1]. This model is based on the test results of 261 groups of reinforced concrete. The seismic damage is modeled via using a double parameter combination of the maximum deformation and cumulative hysteresis energy dissipation, and expressed as

$$
\begin{gathered}
D=\frac{\delta_{m}}{\delta_{u}}+\frac{\beta}{\delta_{u} Q_{y}} \int d E, \\
D=\frac{\delta_{m}}{\delta_{u}}+\beta \int\left(\frac{\delta}{\delta_{u}}\right)^{\alpha} \frac{d E}{E_{c}(\delta)} .
\end{gathered}
$$

$\delta_{u}$ is ultimate deformation under monotonic loading; $\delta_{m}$ is maximum deformation under earthquake; $Q_{y}$ is calculated yield strength (if $Q_{u}$ is smaller than $Q_{y}, Q_{y}=Q_{u}$ ); $d E$ is incremental absorbed hysteretic energy, and $\alpha, \beta$ are nonnegative parameters. Under elastic response, the value of $D$ should theoretically be zero; $D \geq 1.0$ signifies complete collapse or total damage.

Park and Ang represented the effect of cyclic loading on structural damage by the parameter $\beta$. The absorbed hysteretic energy (excluding potential energy) was integrated up to the failure point for 261 groups of cyclic test data from columns and beams. Only those in which a sudden failure was clearly observed or gradual failure could be identified from the envelope curve were included.

When calculating the damage index, the load-deformation curve for each test is traced up to the failure point; at the point of failure $(D=1)$, the corresponding value of $\beta$ is evaluated. In fact, these $\beta$ values also depend on the value of local plastic rotation supply and the concrete strengths beyond. Based on the calculated $\beta$ values [1], a negative correlation was observed between $\beta$ and the confinement ratio, $\rho_{w}$, and weak positive correlations were observed between $\beta$ and the shear span ratio, $l / d$, longitudinal steel ratio, $\rho_{l}$, and axial stress, $n_{0}$. Consider

$$
\begin{gathered}
\beta=\left(-0.447+0.73 \frac{l}{d}+0.24 n_{0}+0.314 \rho_{l}\right) \times 0.7^{\rho_{w}}, \\
\beta=\left(-0.165+0.0315 \frac{l}{d}+0.131 \rho_{l}\right) \times 0.84^{\rho_{w}} .
\end{gathered}
$$

In which, $l / d$ is shear span ratio (replaced by 1.7 if $l / d<1.7$ ); $n_{0}$ is normalized axial stress (replaced by 0.2 if $n_{0}<0.2$ ); $\rho_{l}$ is longitudinal steel ratio as a percentage (replaced by $0.75 \%$ if $\rho_{l}<0.75 \%$ ); and $\rho_{w}$ : confinement ratio, (replaced by $2.0 \%$ if $\rho_{w}>2.0 \%$ ). Table 1 shows the correlation between $\beta$ values from the model and the extent of damage.

2.2. Serviceable Range of Double Parameters Damage Model. Park and Ang proposed their model based on a large number of test data, covering the following range of parameters: $1.0<$ $l / d<6.6 ; 0.2<\rho_{w}<2.0 ; 0<n_{0}<0.52 ; 15.84 \mathrm{~N} / \mathrm{mm}^{2}<$ $f_{c}^{\prime}<41.34 \mathrm{~N} / \mathrm{mm}^{2}$; and $0.04<\rho_{l}<0.45$. They used standard compressive tests with cylindrical samples $(150 \mathrm{~mm}$ in diameter, $300 \mathrm{~mm}$ high) to determine the compressive strength and the failure strength. Beolchini et al. [3], taking test data for concrete columns under repeated loading cycles, believe that the value of $\beta$ depends on $\rho_{w}, \rho_{l}, \lambda=l / d$ (shear span), and $N / f_{C} A_{C}=n_{0}$ (axial compression ratio) as given in the following expression:

$$
\beta=\left(-0.28+0.06 \lambda+0.47 n_{0}+0.19 \rho_{l}\right) \times 0.66^{\rho_{w}} .
$$

More recently, high strength concrete $\left(f_{c}^{\prime}>41.34 \mathrm{~N} /\right.$ $\mathrm{mm}^{2}$ ) has been widely used in engineering; such concrete is beyond the strength range of Park and Ang's model. So, the parameters for the damage model expression of high strength concrete must be adapted. These parameters can then be assessed to determine the damage mechanism, and an appropriate extension created for the damage calculation program.

Relevant tests of high strength concrete columns have been performed by authors, including component design, seismic tests, design of loading devices, and evaluation of the test data to determine the loading mechanism, failure mode, $P-\Delta$ curve, ductility coefficient, and yield displacement. The tests data are presented in reference [4]. Ductility is an important indicator of high strength, constrained, concrete. The comparison between component stiffness degradation, strength degradation, and ductility is shown in Figures 2 and 3.

2.3. Calculating Coefficient of Cyclic Loading Effect $\beta$. Defining $\beta_{1}$ as that calculated using formula (3) and $\beta_{2}$ as that calculated using formula (5), failure points can be obtained from $P-\Delta$ curves of each test extrapolating to the damage point, $D=1$. Then, values of the damage parameter $\beta_{3}$ can then be calculated; see Table 2 . Then, the comparison of parameters $\beta_{1}, \beta_{2}$, and $\beta_{3}$ for a variety of values of beam 


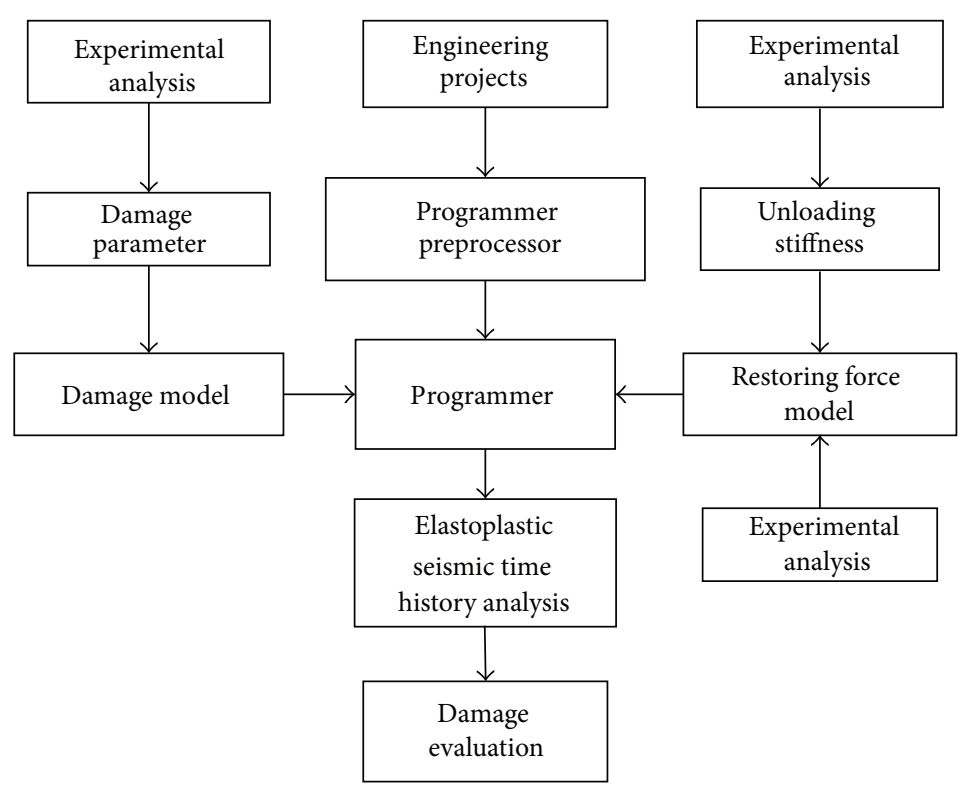

Scheme 1: Programming flowchart.

TABLE 1: Damage evaluation rules from Park and Ang model based on value of $\beta$.

\begin{tabular}{|c|c|c|c|c|}
\hline Damage model & Intact & Medium damage & Serious damage & Collapsed \\
\hline Park and Ang model & & $\begin{array}{c}0-0.4 \\
\text { (damage which can be repaired) }\end{array}$ & $\begin{array}{c}0.4-1.0 \\
\text { (damage which cannot be repaired) }\end{array}$ & $>1.0$ \\
\hline
\end{tabular}

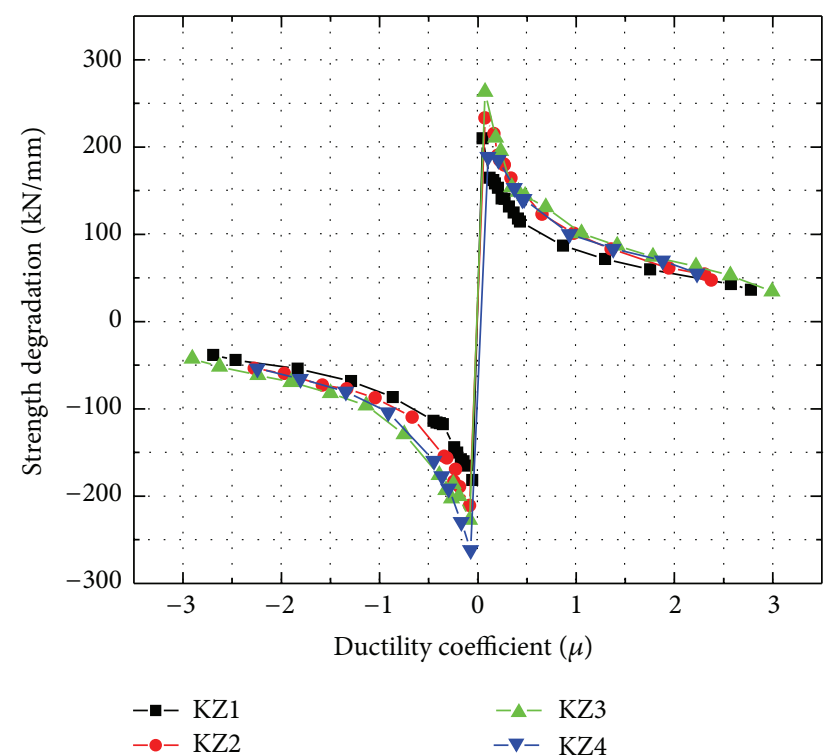

FIGURE 2: Relationship between stiffness degradation and ductility coefficient.

stiffness coefficient, KZ, is shown in Figure 4. The trends in the theoretical values $\left(\beta_{1}, \beta_{2}\right)$ and the experimental regression value $\left(\beta_{3}\right)$ are consistent. However, formulas (3) and (5) do not adequately consider the effect of the greater strength of high strength concrete; the influence of the concrete strength grade on the component ductility and energy consumption

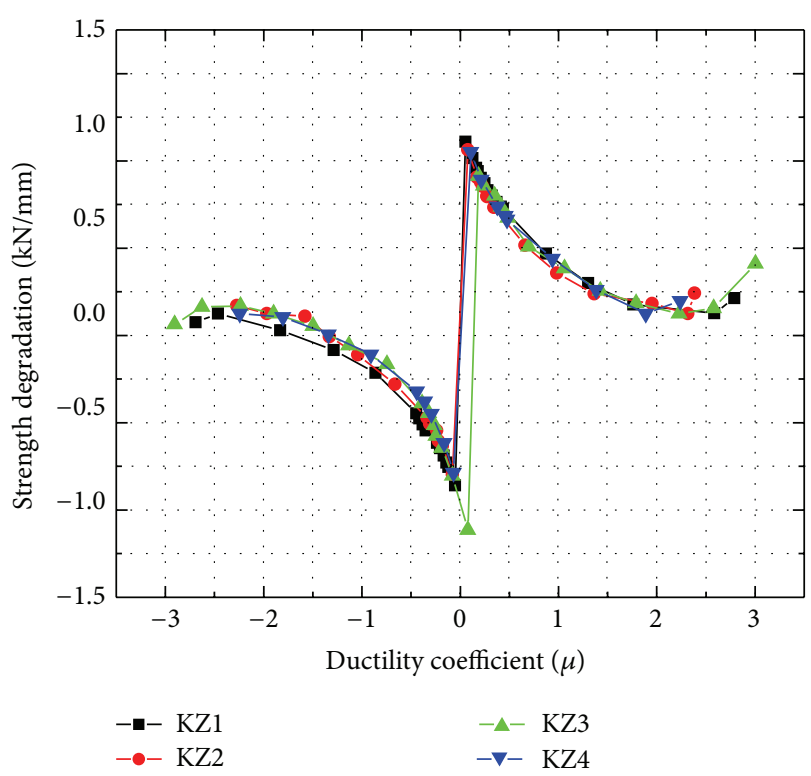

FIGURE 3: Relationship between strength degradation and ductility coefficient.

is quite significant. Component tests are therefore necessary for determining the appropriate parameters for high strength concrete. Table 2 shows the parameters obtained by fitting the expression $\beta\left(\lambda, n, \rho_{l}, \rho_{w}\right)$ for high strength concrete columns in the following procedure: (1) calculate formula (1) using $\beta_{1}$ evaluated from formula (3); (2) calculate formula (2) using 
TABLE 2: Calculation of $\beta$ (parameter of damage model for cyclic loading).

\begin{tabular}{lcccccccc}
\hline Specimen & $\begin{array}{c}\delta_{u} \\
\mathrm{~mm}\end{array}$ & $\begin{array}{c}\mathrm{Q}_{y} \\
\mathrm{kN}\end{array}$ & $\begin{array}{c}\delta_{m} \\
\mathrm{~mm}\end{array}$ & $\begin{array}{c}\int d E \\
\mathrm{kN} \cdot \mathrm{mm}\end{array}$ & $\begin{array}{c}\mathrm{Q}_{y} \delta_{u} \\
\mathrm{kN} \cdot \mathrm{mm}\end{array}$ & $\beta_{3}$ & Double parameters damage model & Modified model \\
\hline TS-1 & 6.51 & 223 & 2.74 & 8292.0 & 1451.73 & 0.104 & 6.994 & 0.941 \\
TS-2 & 6.25 & 236 & 2.41 & 6053.0 & 1475 & 0.144 & 10.028 & 0.929 \\
TS-3 & 6.25 & 269 & 2.43 & 9619.0 & 1681.25 & 0.101 & 6.857 & 0.950 \\
TS-4 & 5.62 & 241 & 2.18 & 5120.0 & 1354.42 & 0.153 & 625 & 0.912 \\
\hline
\end{tabular}

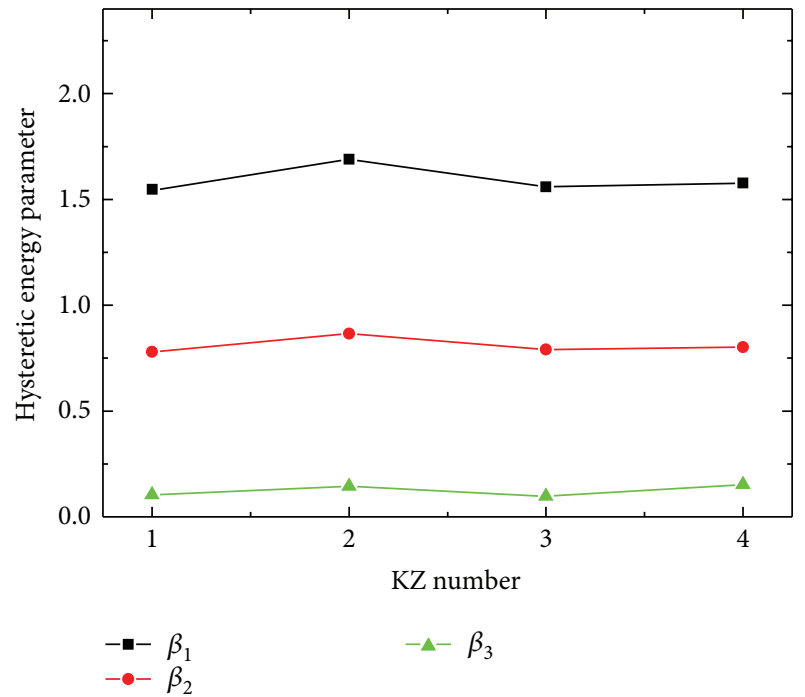

FIGURE 4: Comparison of values of $\beta$ (parameter of damage model) obtained with different models.

$\beta_{2}$ evaluated from formula (5); (3) extrapolate each test curve to the failure point, and finally (4) determine the value at the damage point. The intermediate calculations are given in Table 2. Consider

$$
\beta=\left(-0.447+0.73 \frac{l}{d}+0.24 n_{0}+0.314 \rho_{l}\right)^{\gamma} \times 0.7^{\rho_{w}} .
$$

Formula (6) was used to calculate modified parameters for the deformation-energy damage model. These parameters were then used in the evaluation of testing member, and the new damage index was obtained, as shown in Table 2. The experimentally observed parameters-structural member ruptures, yield, and the final state-correlated well with the damage index. The damage index is close to 1 when the structure fails. The observed phenomena during the tests corresponded well with the predictions from the damage index. While, Park and Ang's model damage index at failure had a value more than 1.0.

2.4. Skeleton Curve of High Strength Concrete. Through research on the restoring force model of high strength reinforced concrete columns, we have established a restoring force model which can adequately explain the nonlinear characteristics, using the principle of simplified calculation, in addition to considering the hysteresis characteristics of component, using the degrading trilinear model (Figure 1).
The route and hysteresis movement of the component can be described from the figure by tracing around the figure in the following sequence: $O \rightarrow C \rightarrow C^{\prime} \rightarrow X \rightarrow X^{\prime} \rightarrow \cdots \rightarrow$ $M \rightarrow P \rightarrow M^{\prime} \rightarrow P^{\prime}$. The OC section represents the elastic behavior, the $C X Y$ section is the strengthening, $Y M$ is degradation, $C^{\prime} X^{\prime} Y^{\prime}$ is the reverse strengthening period, and $Y^{\prime} M^{\prime}$ is the reverse degradation period.

The data at key points on the skeleton curve were determined experimentally and then used to initialize an analysis program that is implemented in IDARC.

\section{High Strength Reinforced Concrete Unloading Rigidity and Ductility Coefficient}

3.1. Elastic Principle of Dynamic Unloading Stiffness. The IDARC program for structural damage analysis had been used to simulate the earthquake response of a frame structure collocated with a high strength concrete column. To better simulate the dynamic performance of a high strength concrete structure, the dependency of the unloading stiffness and ductility coefficient is analyzed after being introduced into the IDARC program. Loading and unloading standards can be expressed as follows: loading $\left(\partial \varphi / \partial \varepsilon_{i j}\right) d \varepsilon_{i j}>0$; neutral loading $\left(\partial \varphi / \partial \varepsilon_{i j}\right) d \varepsilon_{i j}=0$; unloading $\left(\partial \varphi / \partial \varepsilon_{i j}\right) d \varepsilon_{i j}<0(\varphi=$ $0)$.

Unloading during structural vibration is complicated, as structure unloading stiffness matrix changes with time, leading to a time varying parameter system. At present, structure elastic-plastic time history analysis generally does not consider the influences that the unloading stiffness and motion state have on each other. These influences mean that the dynamic equations represented by tangent stiffness and secant stiffness are not equivalent, as the matrix is constantly changing during this process.

From the deformation properties and the restoring force model tests of high strength concrete columns, Figure 5 shows the relationship between the structural member stiffness and number of unloading cycles; it indicates that the variation of $K_{u}(x)$ shows changes consistent with linear drag. The unloading stiffness $K_{u}$ of for all samples changes with cycling, implying that the system is not fully elastic. The most important feature is that $d K_{u}(x)$ is approximately constant, although it varies from sample to sample.

3.2. Unloading Stiffness Correction Coefficient. The unloading stiffness degradation used to determine the damage index conforms to observed evolution of structure damage. As the cyclic stress presenting in structural member, the strain $\varepsilon$ can 


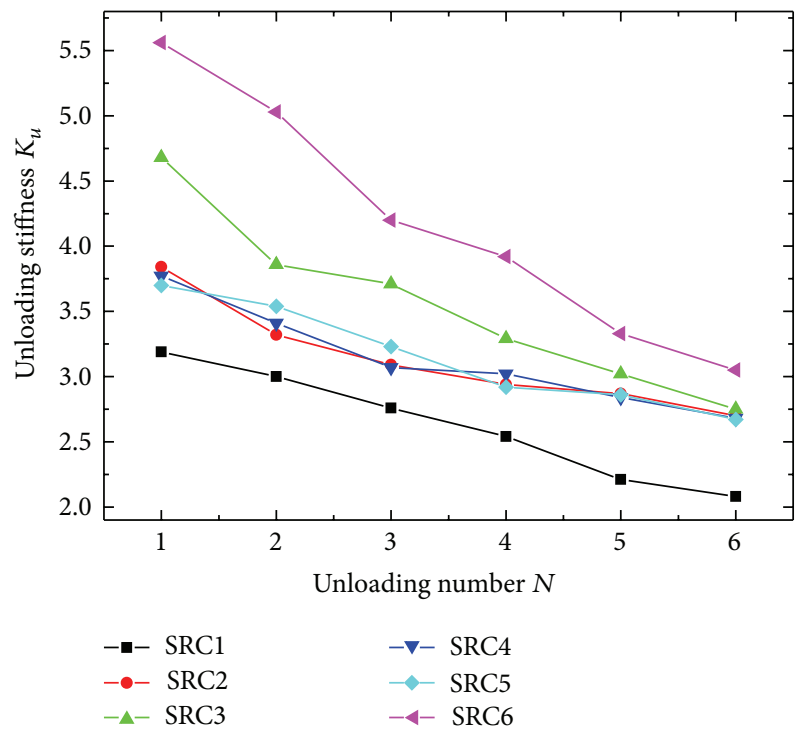

FIgURE 5: Measured $K_{u}$ and unloading number.

be divided into reversible strain $\varepsilon_{e}$ and irreversible strain $\varepsilon^{\prime}$ and $\varepsilon^{\prime}$ includes the plastic strain $\varepsilon_{p}$ and the residual strain due to unrecoverable damage, $\varepsilon_{u}$. From the principle of damage,

$$
\sigma=E(1-\nu D) \varepsilon_{e}=E(1-\nu D) \Delta_{e} .
$$

In formula (7), destruction of the member is defined as $D=1$. For the damage model, $D$, we have used the deformation-energy double parameter combination; $v$ is only taken into account by the combination of factors of the maximum displacement damage coefficient $(0.5 \leq v<$ 1.0). According to independent state variables principle in thermomechanics, the $P-\Delta$ state during damage evolution can be expressed as

$$
\begin{gathered}
F=K_{0}(1-\nu D) \Delta_{e}=K_{0}(1-\nu D)\left(\Delta-\Delta_{p}-\Delta_{u}\right), \\
\nu D=1-\frac{F}{K_{0}\left(\Delta-\Delta_{p}-\Delta_{u}\right)}=1-\frac{K_{u}(x)}{K_{0}} .
\end{gathered}
$$

Formula (8) implies that using unloading stiffness $K_{u}(x)$ to describe the structure damage value $D$ is feasible. For ductile members $(2.0<\mu<4.0)$, assuming that the damage function $D=f_{D}\left(x_{1}, x_{2}, \ldots, x_{n}\right)$ is a monotonically increasing function, we can obtain the following from formula (8):

$$
K_{u}(x)=\left[1-v f_{D}\left(x_{1}, x_{2}, \ldots, x_{n}\right)\right] K_{0},
$$

where for the $i$ th cycle, unloading stiffness is $K_{u_{i}}$ and elastic stiffness ratio is $\eta_{i}$. At cycle $(i+1)$, the unloading stiffness is $K_{u_{i+1}}$ and elastic stiffness ratio is $\eta_{i+1} . \xi$ is defined as the ratio for the $i$ th and $(i+1)$ th cycles:

$$
\xi=\frac{\eta_{i+1}}{\eta_{i}}
$$

Figure 6 charts the relationship between the measured value $\xi$ and cycle number, $N$. The value of $\xi$ remained steady

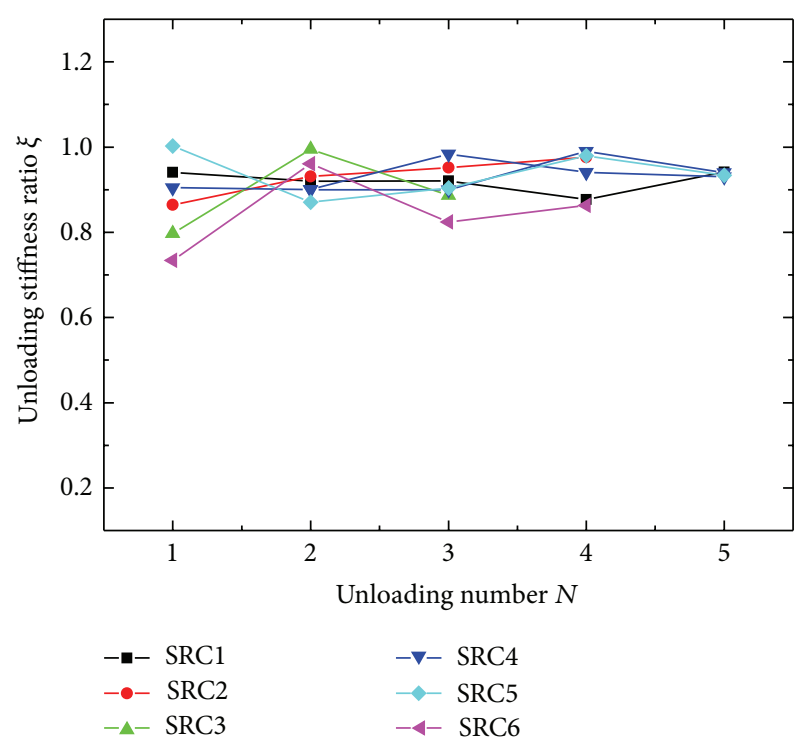

Figure 6: Measured $\xi$ and unloading number.

between $0.85 \leq \xi \leq 0.95$, implying that this parameter can be fixed during modeling; we suggest $\xi=0.9$ for HSC. The test specimens reflect the phenomenon of degeneration of unloading stiffness with increasing displacement amplitude and can explain the fact that for an actual component the response excursion is always larger in one direction (i.e., offset), and eventually the accumulated errors as a result of this can lead to computational instability. Dynamic adjustment of unloading stiffness is simple but practically important.

\section{Damage Evaluation of Highly Confined Concrete Structure Damage Evaluation Based on IDARC}

4.1. Design Information of High Column Structure. In this paper, we model a structure comprising a six-floor frame of cast-in-situ high strength reinforced concrete. The strength grades of the concrete beams are C60-C80 and the main reinforcement and lateral reinforcement are $\operatorname{HRB} 400\left(f_{y}\right)$, where the effects on structure ductility while utilizing HRB400 as reinforcement in high strength concrete have been studied to be limited under certain conditions $[5,6]$. The columns use symmetric steel reinforcement, the cover thickness is $30 \mathrm{~mm}$, and the gravitational load of each floor is: $G_{1}=6800 \mathrm{kN}$, $G_{2}=G_{3}=G_{4}=G_{5}=G_{6}=6600 \mathrm{kN}$. The earthquake intensity is at level VIII (Liedu scale, CSIS). According to the structure facade height, earthquake intensity, and design ground acceleration, the seismic design parameters are design grade 2 , site category II, and design group 1 (feature period $T_{g}=0.35 \mathrm{~s}$ ). Therefore, the average material strength of the high strength concrete is necessary to consider the dynamic response characteristics (including the restoring force) of the structural members; as the natural period of structure is $T_{1}=0.49 \mathrm{~s}$, the design ground acceleration is $0.15 \mathrm{~g}$. 
The axial forces applied to each column in the structure are computed by elastic analysis. This paper adopts two indices to characterize the wave, the design characteristic period of site structure $T_{g}$, and structure basic natural period $T_{1}$. To choose the earthquake duration and natural period for the model, we have selected two strong earthquake records P0151 and P0994 from the PEER Strong Motion Database [7], the EL Centro wave (Figure 7) which is widely used in engineering, and also the RH4TG040 artificial seismic wave, ThiTG040 natural seismic wave, and TH2TG040 natural seismic wave from the EPDA module [8].

4.2. Damage Programming. IDARC is from the Earthquake Engineering Research Centre of the State University of New York at Buffalo and is widely used for various types of nonlinear dynamic response time history analysis and damage analysis of structures. Details of our IDARC analysis will be given below.

(1) Hysteretic Rules Model. The program provides a threeparameter Park's model, bilinear hysteretic model, Kelvin's model, Maxwell's model, and smooth hysteretic model. For this paper, we have chosen a three-line attenuation model created by authors; all control information required by the preprocessor is obtained from the experimental skeleton curve.

(2) Nonlinear Dynamic Analysis. Nonlinear dynamic analysis is carried out using a combination of the Newmark-beta integration method, and the pseudoforce method. The equation is solved numerically, according to

$$
\begin{aligned}
{[M] } & \{\Delta \ddot{u}\}+[C]\{\Delta \dot{u}\}+\left[K_{t}\right]\{\Delta u\} \\
= & -[M]\left(\left\{L_{h}\right\} \Delta \ddot{x}_{g h}+\left\{L_{v}\right\} \Delta \ddot{x}_{g v}\right)-\left\{\Delta P_{I W}\right\} \\
& +c_{\text {corr }}\left\{\Delta F_{\text {err }}\right\},
\end{aligned}
$$

where $[M]$ is the lumped mass matrix of the structure; $[C]$ is the viscous matrix of the structure; $\left[K_{t}\right]$ is the tangent stiffness matrix; $\{\Delta u\},\{\Delta \dot{u}\}$, and $\{\Delta \ddot{u}\}$ are the incremental vectors for displacement, velocity, and acceleration in the structure; $\left\{L_{h}\right\}$ and $\left\{L_{v}\right\}$ are the allocation vectors for the horizontal and vertical ground accelerations; $\Delta \ddot{x}_{g h}$ and $\Delta \ddot{x}_{g v}$ are the increments in the horizontal and vertical ground accelerations; $\mathcal{c}_{\text {corr }}$ is a correction coefficient; and $\left\{\Delta F_{\text {err }}\right\}$ is the vector containing the unbalanced forces in the structure. At the end of step $t+\Delta t$, the difference between the restoring force calculated using the hysteretic mode $\{R\}$ and the restoring force considering no change in stiffness during the step $\left\{R^{\prime}\right\}$ yields the residual force $\left\{\Delta F_{\text {err }}\right\}=\{R\}-\left\{R^{\prime}\right\}$.

This corrective force is then applied for the next time step of the analysis. The unbalanced forces are computed when moments, shears, and stiffness are being updated in the hysteretic model. We selected a step length of 0.02 seconds, to produce smaller changes at each step and thus avoid larger residual forces, which could lead to unstable calculations.

(3) Damage Index. IDARC incorporates three models for damage index, (a) classical Park-Ang's model; (b) a model based on low cycle fatigue damage characteristics; and (c)
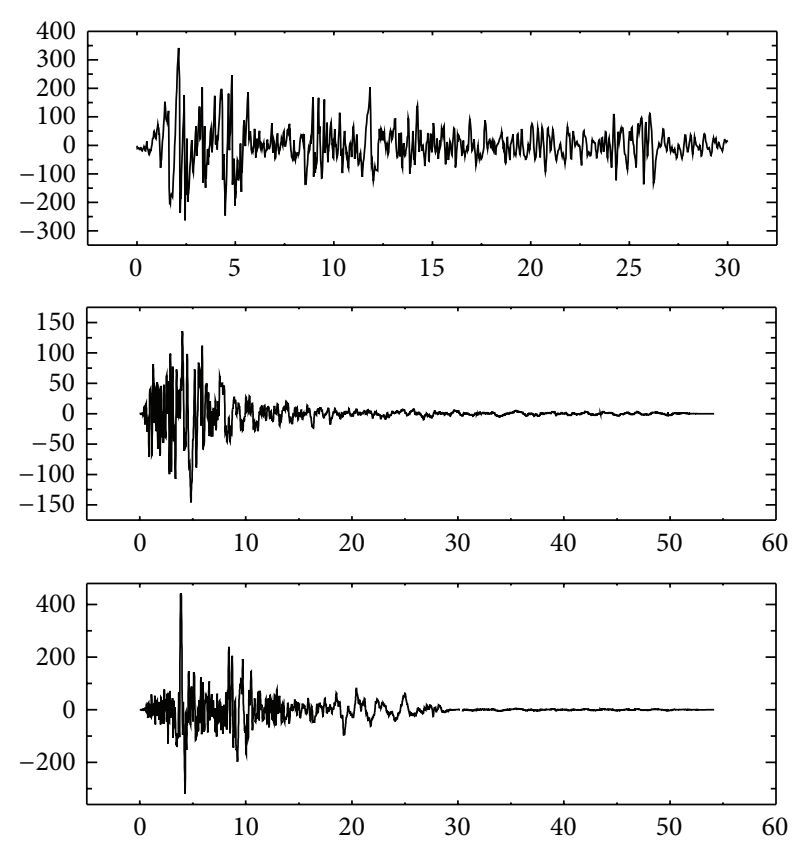

Figure 7: El Centro, P0151 and P0994 seismic waves.

according to the structural basic cycle for the overall structure damage index. This paper used the modified double parameters damage index and calculated the indices using the embedded computing methods (a), (b), and (c) for comparison.

\subsection{Structural Nonlinear Dynamic Analysis Results}

4.3.1. The Maximal Displacement and Angular Displacement between Floors. This paper selects high strength RC structures as an example to investigate dynamic analysis, study the seismic performance, and evaluate the degree of damage. Under seismic action (3 waves of structure PEER ground motion, 2 waves of EPDA ground motion, 1 wave of artificial seismic wave and the SATWE program), the maximum displacement of each floor and the maximum angular displacement between the floors are shown in Figure 8. For different input seismic waves, the trends in the maximum displacements and angular displacements of floors are consistent. It suggests that the damage assessment program is reliable. The maximum angular displacements appeared in floor 3 and floor 2, and the angular displacement exceeds the limit of 0.02 by code, but no obvious weak floors are observed.

4.3.2. Plastic Hinge Law and Damage Distribution. The implemented program provides the structural damage index and plastic hinge distribution for each seismic wave. The structural plastic hinge distribution and sequence of their appearances under earthquake ground motion PEER are shown in Figure 9, and the profile of the damage distribution is in Figure 10. The behavior of the structural damage distribution and structure plastic hinge distribution are almost identical. A greater damage index means that the members 

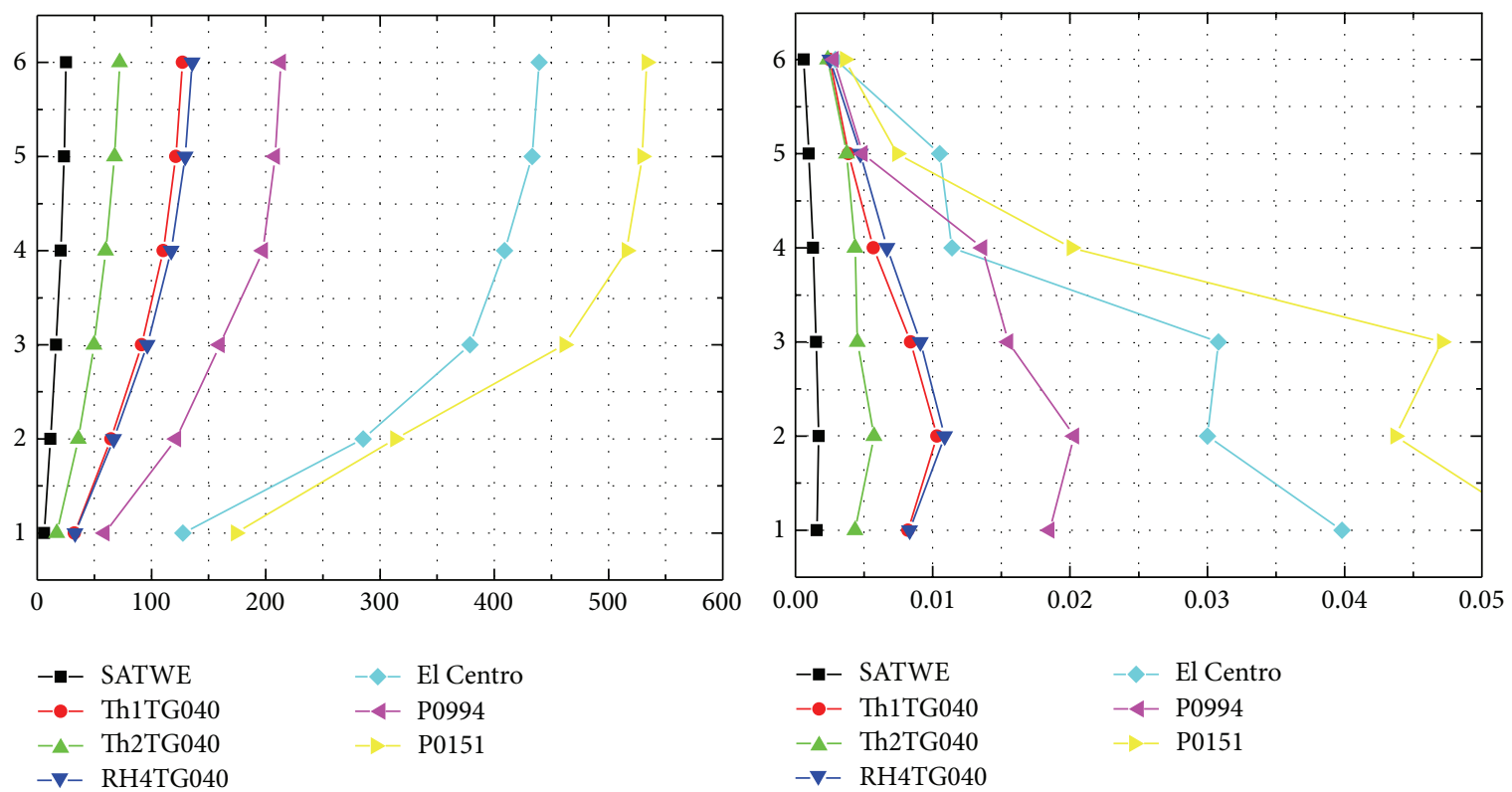

FIGURE 8: Maximum floor displacement and story drift angle of building in seismicity basic intensity 8 area.
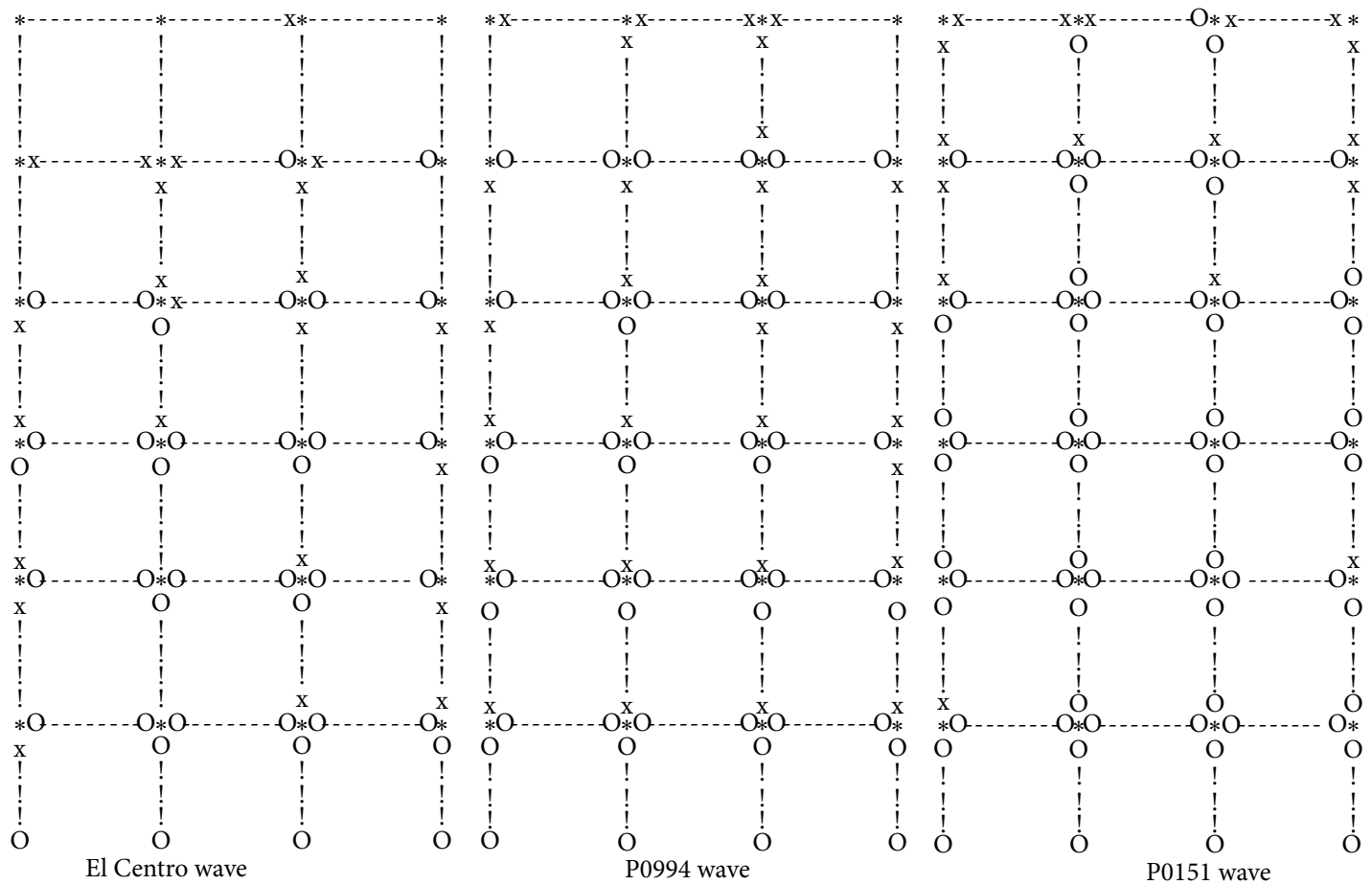

Final state of frame

- Beam

! Column

$\mathrm{x}$ Cracking
O Plastic hinge developed

* Local failure (exceed criteria)

FIGURE 9: Plastic hinge distribution of building. 

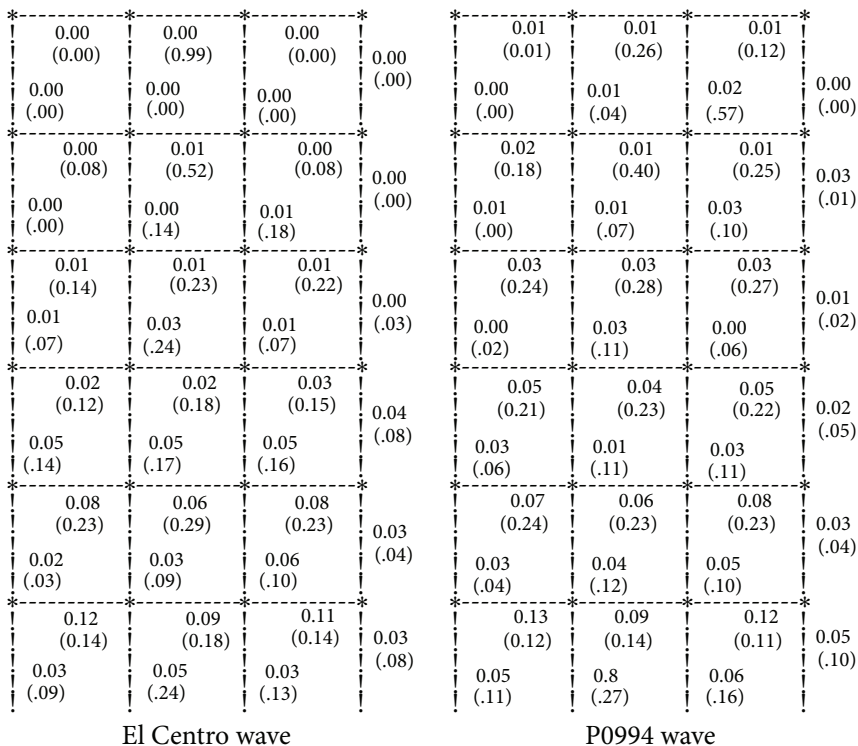

\begin{tabular}{|c|c|c|c|}
\hline $\begin{array}{c}0.01 \\
(0.05)\end{array}$ & $\begin{array}{l}0.01 \\
(0.12)\end{array}$ & $\begin{array}{l}0.01 \\
(0.07)\end{array}$ & \\
\hline $\begin{array}{l}0.03 \\
(.18)\end{array}$ & $\begin{array}{l}0.03 \\
(.18)\end{array}$ & $\begin{array}{l}0.03 \\
(.24)\end{array}$ & $\begin{array}{l}0.03 \\
(.25)\end{array}$ \\
\hline $\begin{array}{r}0.04 \\
(0.20)\end{array}$ & $\begin{array}{r}0.02 \\
(0.20)\end{array}$ & $\begin{array}{r}0.04 \\
(0.20)\end{array}$ & 0.02 \\
\hline $\begin{array}{l}0.04 \\
(.06)\end{array}$ & $\begin{array}{l}0.02 \\
(.18)\end{array}$ & $\begin{array}{l}0.05 \\
(.17)\end{array}$ & $(.02)$ \\
\hline $\begin{array}{c}0.05 \\
(0.23)\end{array}$ & $\begin{array}{r}0.04 \\
(0.21)\end{array}$ & $\begin{array}{r}0.06 \\
(0.24)\end{array}$ & \\
\hline $\begin{array}{l}0.03 \\
(.06)\end{array}$ & $\begin{array}{l}0.08 \\
(.15)\end{array}$ & $\begin{array}{l}0.06 \\
(.09)\end{array}$ & \\
\hline $\begin{array}{l}.0 .12 \\
(0.21)\end{array}$ & $\begin{array}{r}0.09 \\
(0.23)\end{array}$ & $\begin{array}{c}0.13 \\
(0.24)\end{array}$ & \\
\hline $\begin{array}{l}0.08 \\
(.06)\end{array}$ & $\begin{array}{l}0.06 \\
(.11)\end{array}$ & $\begin{array}{l}0.07 \\
(.12)\end{array}$ & $(.03)$ \\
\hline $\begin{array}{r}0.19 \\
(0.28)\end{array}$ & $\begin{array}{c}0.11 \\
(0.29)\end{array}$ & $\begin{array}{r}0.18 \\
(0.26)\end{array}$ & 0.02 \\
\hline $\begin{array}{l}0.02 \\
(.02)\end{array}$ & $\begin{array}{l}0.03 \\
(.06)\end{array}$ & $\begin{array}{l}0.03 \\
(.06)\end{array}$ & (.03) \\
\hline $\begin{array}{r}0.16 \\
(0.17)\end{array}$ & $\begin{array}{c}0.11 \\
(0.17)\end{array}$ & $\begin{array}{r}0.13 \\
(0.14)\end{array}$ & \\
\hline $\begin{array}{l}0.03 \\
(.07)\end{array}$ & $\begin{array}{l}0.06 \\
(.22)\end{array}$ & $\begin{array}{l}0.04 \\
(.14)\end{array}$ & \\
\hline
\end{tabular}

FIgURE 10: Damage index statistics of frame.

P0151 wave

yield earlier and the plastic rotation is larger and vice versa. The damage to columns is light, the damage level of most columns is "medium destruction," and the performance of the high-performance concrete is satisfactory. While the damage in the beams is much serious, the distribution of the damage index reflects the seismic design principle of "strong column, weak beam". Apart from the top floor, all beam ends act as plastic hinges, whilst only the column bottoms and a few centers of columns show hinge behavior. The beams act as hinges earlier than columns, nearly forming an overall symmetrical beam hinge system. The structure performance measured by the quantitative damage index is more reliable than displacement-based design.

The shear-displacement hysteresis curves for the bottom of the structure are shown in Figure 11. Qualitative analysis of the hysteric performance of each floor can be performed based on the lateral displacement-shear hysteresis relationships under the action of the shock wave. Preliminary analysis of the graphs shows that the bottom layer has yielded, and the extent of rigidity degradation shows that the first shock transcends beyond destruction and the maximum displacement appears only for a few seconds. Most of the time, the displacement is relatively small, and the plastic energy dissipation and cumulative plastic deformation are small.

4.3.3. Seismic Damage Analysis of Whole Structure. The modified parameter damage model was used to calculate damage parameters for all columns in each floor of the frame structure under the earthquake waves. The results are shown in Table 3. Both the results and value range of the modified damage model calculation are close to those observed in real damaged structures. Getting instantaneous snapshots from the program during time history analysis, we can calculate the instantaneous damage index for the whole structure as a function of the time period. We find that for this example wave used the damage index is

$$
\mathrm{DI}=1-\frac{\left(T_{0}\right)_{\text {initial }}}{\left(T_{0}\right)_{\text {equivalent }}}=1-\frac{0.49}{1.410}=0.652
$$

where $\left(T_{0}\right)_{\text {initial }}$ is the initial fundamental period and $\left(T_{0}\right)_{\text {equivalent }}$ is the equivalent fundamental period. The overall damage can reflect more accurately the reaction of the whole structure. This is probably because that, using the vibration frequency attenuation method (i.e., the change in stiffness with time), it accurately simulates the real behavior of structures. The results show that the high strength concrete frame had been damaged, but not up to the extent of complete collapse; it reaches the seismic design goal of not collapsing under a major earthquake. The presented algorithm results in a damage index always less than 1.0. This modified double parameters damage model is correctly describing the performance of damaged structures, because it predicts the results that are quite close to those observed in real damaged structures.

\section{Conclusions}

In this paper, based on the deformation-energy damage model and using experimental test data, we determined the expressions for the coefficient of the cyclic load effect and values required for the double parameter damage model of members of a high strength reinforced concrete column member. Ductility is the key index of high-performance concrete, as found by the analysis of the relationships between stiffness degradation, strength degradation, and ductility. A model of the restoring force was used; this model allowed extrapolation of the data to the point of failure to obtain 

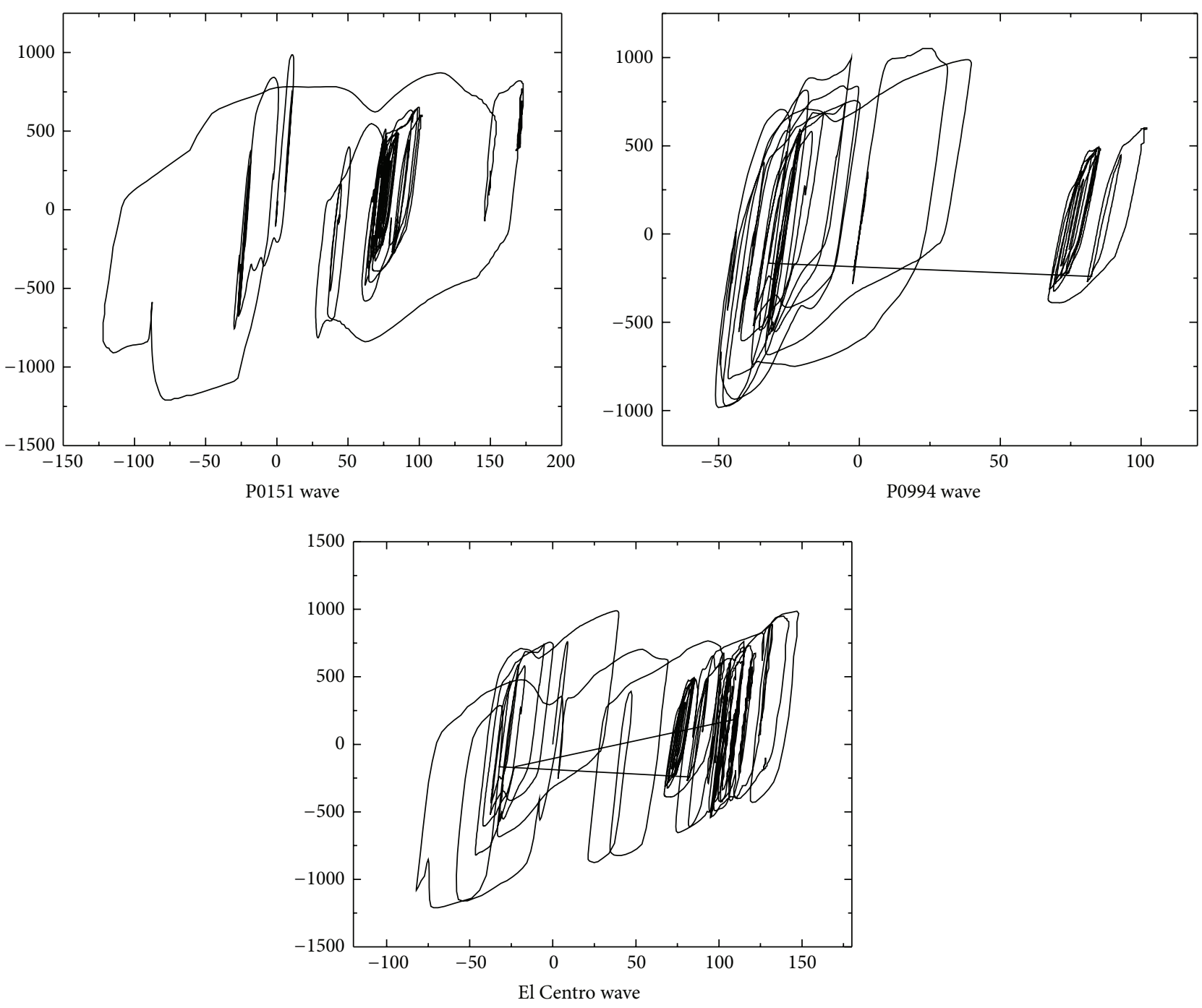

FIGURE 11: Base shear-drift hysteretic curve of building first floor.

the restoring force. A trilinear model was employed to describe damage.

Generally, the elastic-plastic time history analysis does not consider the relationship between unloading stiffness and motion state which influence each other. Thus, we evaluate the structure elastic-plastic time history analysis by introducing the unloading correction coefficient, which is a parameter that characterizes the change with time of the unloading stiffness matrix structure, and solve the equivalent problem between the structural dynamic equation indicated by tangential stiffness and secant stiffness. This gives a good description of the elastic-plastic structure vibration dynamic process, which can be used to describe the concrete structure unloading in the dynamic elastic-plastic state. We then implemented these modifications into the elastic-plastic time history analysis in IDARC program.

Presenting the case study of a high strength RC frame, the member dynamic response characteristics of the restoring force was calculated from the material average strengths, where the longitudinal bar and stirrup bar were high strength bar and the concrete strength of the beam-column was high. The structural damages were observed under various seismic waves, including two strong artificial seismic wave records from the PEER library, the El Centro wave, two natural seismic waves, and one artificial seismic wave from EPDA. Dynamic analysis was used to analyze the seismic performance and evaluate the degree of damage. Under a strong earthquake, the maximum displacement and angular displacement between floors are consistent. The maximum angular displacement is more than limits by code, but there is no obvious weak floor; the damage to the base of the structure accumulates up until the maximum impact of reaction. The distribution of the damage index reflects the seismic design criterion of "strong column, weak beam," nearly forming a symmetrical beam hinge system. The lateralshear hysteresis curve is showing the yielding and the stiffness degradation degree. The displacements only appear to be exceeding initially and to be later small generally. 
TABle 3: Damage index of middle columns in each floor under seismic waves.

\begin{tabular}{|c|c|c|c|c|c|c|c|}
\hline Earthquake wave & & $\begin{array}{c}\delta_{u} \\
\mathrm{~mm}\end{array}$ & $\begin{array}{c}F_{y} \\
\mathrm{kN}\end{array}$ & $\begin{array}{c}\delta_{m} \\
\mathrm{~mm}\end{array}$ & $\int_{\mathrm{kN} \cdot \mathrm{mm}} d E$ & IDARC & Modified damage model \\
\hline $\mathrm{P}$ & 1 & 173 & 362 & 102 & $4.07 E+04$ & 0.205 & 0.65 \\
\hline 0 & 2 & 135 & 419 & 60.8 & $1.01 E+04$ & 0.181 & 0.77 \\
\hline 1 & 3 & 124 & 111 & 44.7 & $1.62 E+04$ & 0.275 & 0.76 \\
\hline 1 & 4 & 58.6 & 245 & 14.6 & $3.81 E+03$ & 0.198 & 0.79 \\
\hline \multirow[t]{2}{*}{5} & 5 & 27.8 & 191 & 19.6 & $1.12 E+03$ & 0.152 & 0.64 \\
\hline & 6 & 140.1 & 404 & 65 & $3.33 E+02$ & 0.134 & 0.56 \\
\hline $\mathrm{P}$ & 1 & 70.1 & 346 & 41.9 & $2.28 E+04$ & 0.081 & 0.5 \\
\hline 0 & 2 & 73.1 & 373 & 43.3 & $2.12 E+03$ & 0.069 & 0.65 \\
\hline 9 & 3 & 60 & 341 & 43.4 & $7.27 E+03$ & 0.131 & 0.65 \\
\hline 9 & 4 & 45.1 & 245 & 29.4 & $3.19 E+03$ & 0.078 & 0.68 \\
\hline \multirow[t]{2}{*}{5} & 5 & 32.5 & 113 & 15.2 & $6.60 E+02$ & 0.06 & 0.48 \\
\hline & 6 & 72.7 & 352 & 40.6 & $3.36 E+02$ & 0.05 & 0.47 \\
\hline$E$ & 1 & 148 & 276 & 69 & $2.54 E+04$ & 0.135 & 0.53 \\
\hline \multirow[t]{5}{*}{$\mathrm{L}$} & 2 & 96.5 & 294 & 68.3 & $4.68 E+03$ & 0.11 & 0.73 \\
\hline & 3 & 98.1 & 221 & 66.1 & $1.01 E+04$ & 0.162 & 0.7 \\
\hline & 4 & 28.8 & 330 & 19.8 & $2.54 E+03$ & 0.1 & 0.71 \\
\hline & 5 & 26.7 & 184 & 13.5 & $7.67 E+02$ & 0.085 & 0.53 \\
\hline & 6 & 30.8 & 212 & 15.8 & $2.08 E-02$ & 0.081 & 0.53 \\
\hline
\end{tabular}

To improve the calculation efficiency, the implementation of the modified damage model in IDARC program was developed and performed well for evaluating highly constrained high strength reinforced concrete structures. Comparison and further validation analysis and evaluation of damage with more software and programs will be done in future work, and more structural members data is necessary in evaluating the more precise correlation between damage model parameters and exact damage to structures.

\section{Conflict of Interests}

The authors of the paper declare that there is no conflict of interests regarding the publication of this paper. The authors do not have a direct financial relation with the commercial identity that might lead to a conflict of interests for any of the authors.

\section{Acknowledgments}

This work is supported by Natural Science Foundation of China (Grant no. 50578066), Natural Science Foundation of Fujian Province of China (Grant no. 2011J01320), and National Special Fund for the Territorial Resources in the Public Interest (no. 201111020-2). The authors sincerely thank them for their support and funding.

\section{References}

[1] Y.-J. Park and A. H.-S. Ang, "Mechanistic seismic damage model for reinforced concrete," Journal of Structural Engineering, vol. 111, no. 4, pp. 722-739, 1985.
[2] M. V. Sivaselvan, E. Yuksel, K. Winkelmann, and A. M. Reinhorn, "Transforming of an existing structural analysis program to the object-oriented framework," Advances in Engineering Software, vol. 40, no. 11, pp. 1131-1139, 2009.

[3] G. C. Beolchini, D. Galeota, M. M. Giammatteo, and M. Zulli, Seismic Behavior of High Strength RC Columns, New Zealand Society for Earthquake Engineering, Aukland, New Zealand, 2000.

[4] H. Lin and Q. Wang, "Seismic behavior on HRB400 highstrength reinforced concrete columns," Journal of Building Structures, vol. S1, no. 1, pp. 36-41, 2008.

[5] K. Yang, Q. Shi, J. Zhao, W. Jiang, and H. Meng, "Study on the constitutive model of high-strength concrete confined by highstrength stirrups," China Civil Engineering Journal, vol. 46, no. 1, pp. 34-41, 2013.

[6] Q. X. Shi, P. Wang, Y. Tian et al., "Experimental study on seismic behavior of high-strength concrete short columns confined with high-strength stirrup," China Civil Engineering Journal, no. 8, pp. 1-8, 2014.

[7] BCUO, PEER Strong Motion Database, 2014.

[8] PKPM, Multi-Layer and High-Rise Building Structure ElasticPlastic Static/Dynamic Analysis Software Push\& EPDA, Chinese Architecture Industry Press, Beijing, China, 2012. 


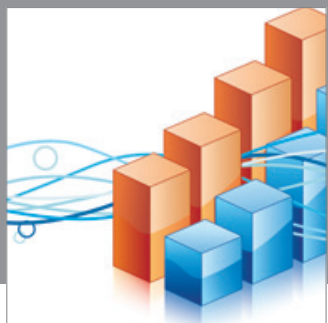

Advances in

Operations Research

mansans

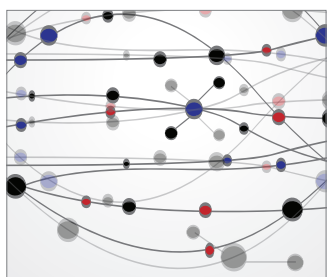

The Scientific World Journal
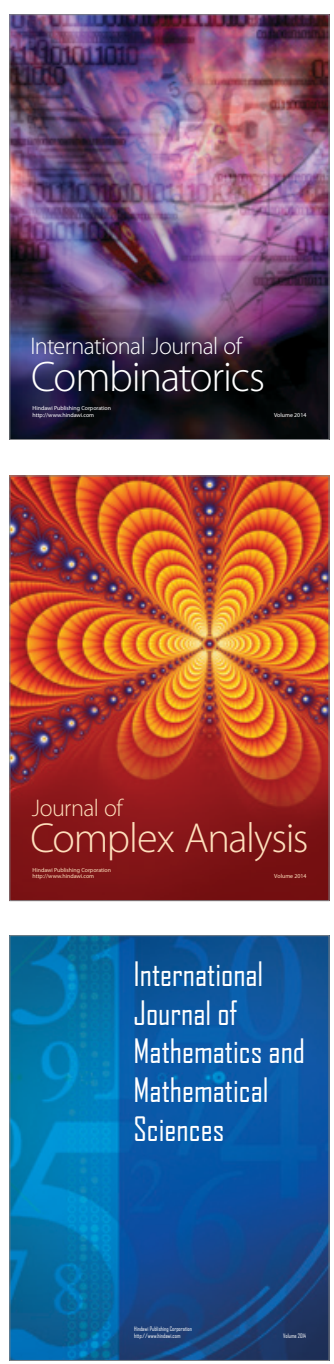
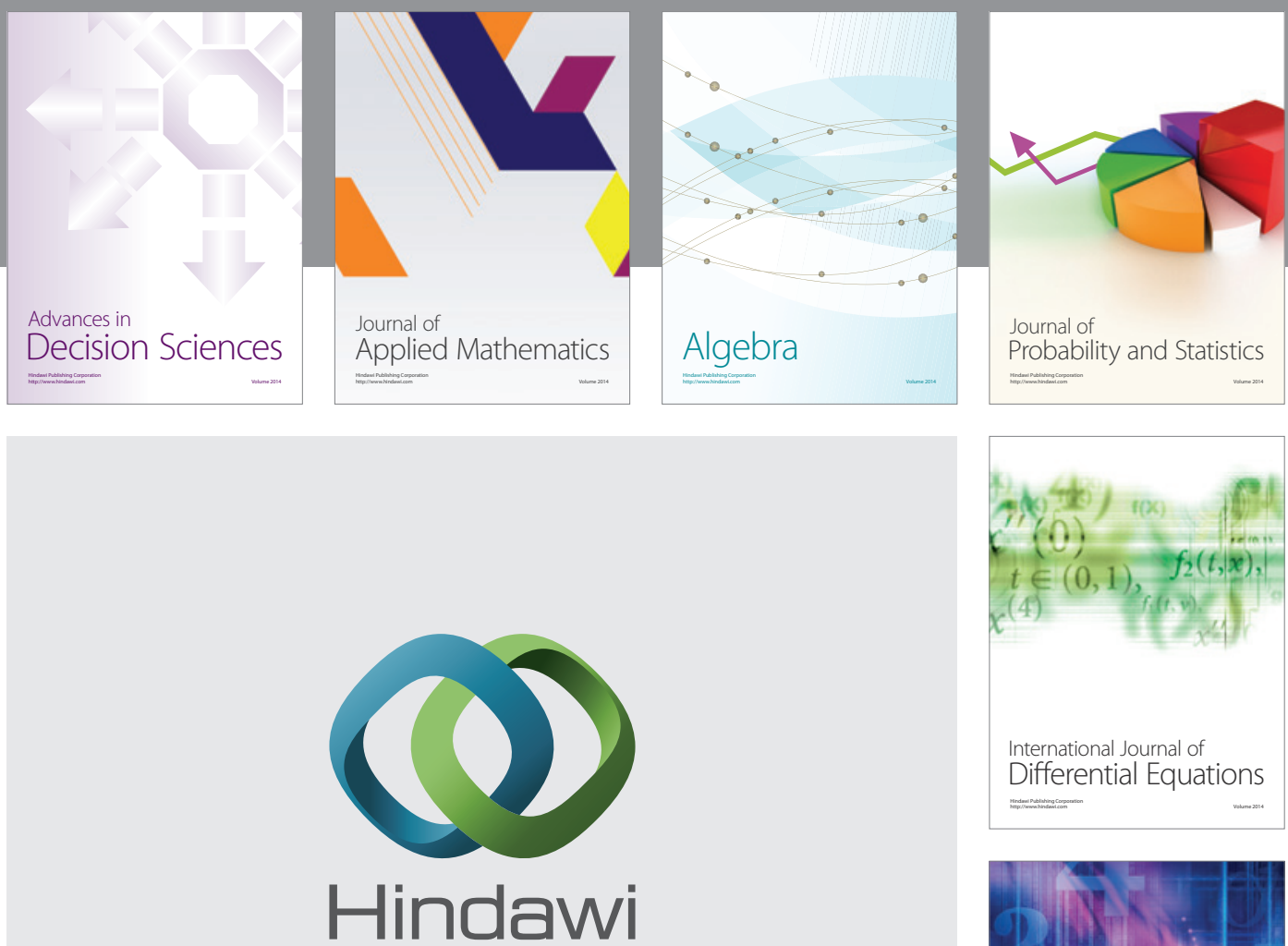

Submit your manuscripts at http://www.hindawi.com
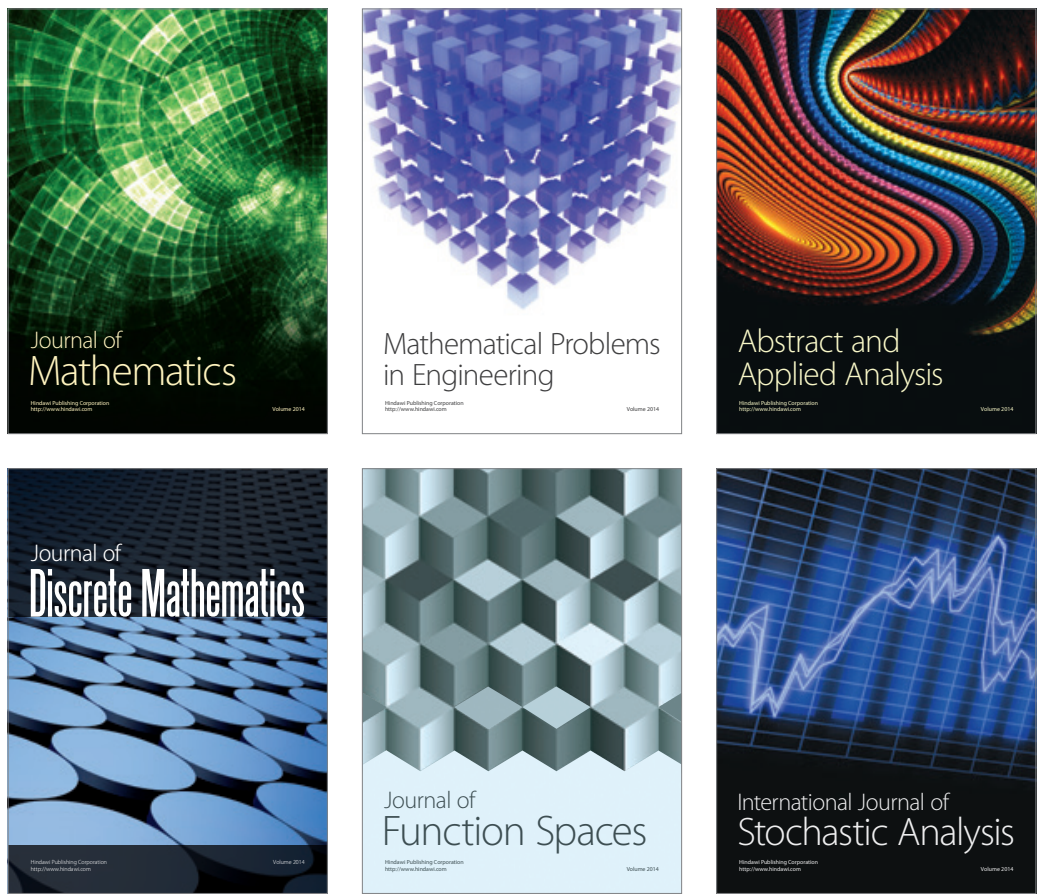

Journal of

Function Spaces

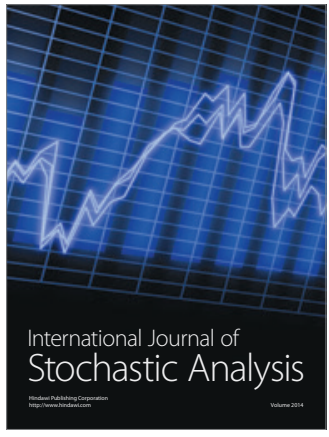

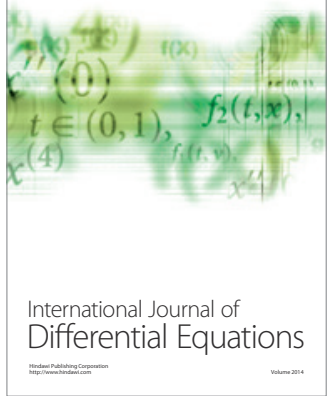
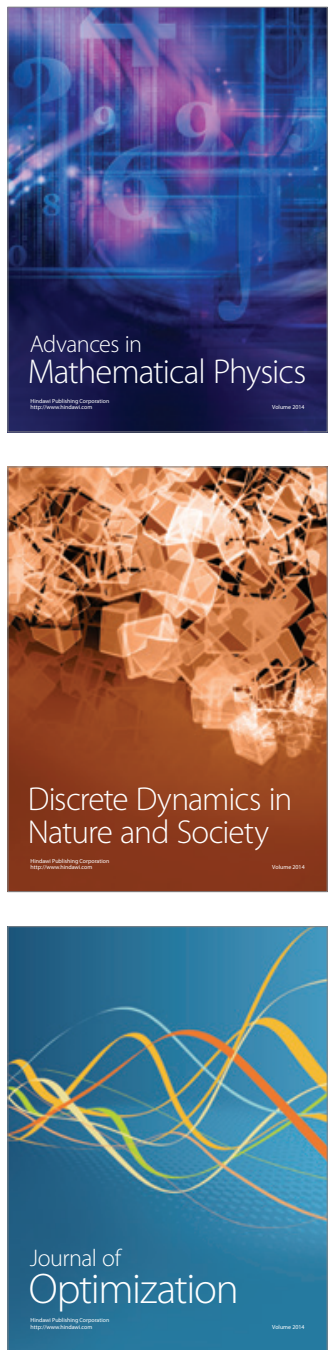